\title{
A Territorialidade do Empreendedorismo: Perspectivas e Desafios para o Empreendedorismo Cultural
}

\author{
The Territoriality of Entrepreneurship: Perspectives and Challenges for Cultural \\ Entrepreneurship
}

\author{
Joyce Neri dos Reis Neves ${ }^{i}$ \\ Orcid: http://orcid.org/0000-0001-8974-4732 \\ Eduardo Paes Barreto Davelii \\ Orcid: http://orcid.org/0000-0003-0610-6474
}

\begin{abstract}
Resumo
Encontramos pesquisas que relacionam o empreendedorismo com questões territoriais e espaciais. Todavia, desconhecemos pesquisas que pensem o empreendedorismo cultural em relação a essas questões. Ora, no contexto das economias culturais e criativas, sustentadas e dinamizadas pelas forças empreendedoras, pensar sua relação com as questões territoriais e espaciais não seria um caminho para tornar o desenvolvimento mais enraizado, político, distinto e robusto? O objetivo desta pesquisa é elaborar e discutir perspectivas e desafios para uma concepção territorial do empreendedorismo cultural. A pesquisa é teórico-conceitual, baseada em uma revisão sistemática das pesquisas acadêmicas publicadas sobre empreendedorismo, empreendedorismo cultural e territorialidade. Os resultados da pesquisa fornecem (a) uma visão integrada de como os conceitos territoriais são utilizados no campo do empreendedorismo, (b) perspectivas espaciais para reorientar novas pesquisas sobre empreendedorismo cultural e (c) uma discussão sobre essa reorientação.
\end{abstract}

Palavras-chave: empreendedorismo; empreendedorismo cultural; territorialidade.

\begin{abstract}
We found research that bound entrepreneurship with spatial and territorial issues. However, we are unaware of research that thinks cultural entrepreneurship in relation to these issues. Now, in the context of cultural and creative economies, sustained and dynamized by entrepreneurial forces, wouldn't thinking about their relationship with territorial and spatial issues be a way to make development more rooted, political, distinct and robust? The objective of this research is to elaborate and discuss perspectives and challenges for a territorial conception of cultural entrepreneurship. The research is theoretical-conceptual, based on a systematic review of published academic research on entrepreneurship, cultural entrepreneurship and territoriality. The survey results provide (a) an integrated view of how territorial concepts are used in the field of entrepreneurship, (b) spatial perspectives to reorient new research on cultural entrepreneurship, and (c) a discussion of this reorientation.
\end{abstract}

Keywords: entrepreneurship; cultural entrepreneurship; territoriality

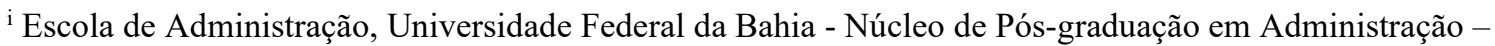
NPGA. E-mail: joyce.nrn@gmail.com

ii Escola de Administração, Universidade Federal da Bahia - Núcleo de Pós-graduação em Administração NPGA. E-mail: davel.eduardo@gmail.com
} 


\section{INTRODUÇÃO}

Embora as discussões sobre empreendedorismo não sejam recentes, quando enfocamos a relação entre empreendedorismo e cultura no contexto do empreendedorismo cultural, as produções permanecem escassas (DAVEL; CORA, 2016; HAUSMANN; HEINZE, 2016; MARINS; DAVEL, 2020b). O empreendedorismo cultural pode ser classificado por meio de várias mobilizações e concepções da cultura: como discurso simbólico, como criação simbólica e como consumo simbólico (DAVEL; CORA, 2016). Dentre essa variedade de possibilidades conceituais, adotamos o conceito de empreendedorismo cultural como a criação e busca de ideias inovadoras por aqueles engajados em atividades artísticas e culturais, e que aplicam, compartilham e distribuem trabalho criativo (ELIAS et al., 2018).

$\mathrm{O}$ tema do empreendedorismo cultural vem sendo constantemente valorizado pelas pesquisas, não só no cenário nacional, mas também no internacional, graças ao seu caráter singular, que o diferencia do empreendedorismo tradicional (MARINS; DAVEL, 2020b). As economias criativas combinam os níveis mais íntimos da identidade pessoal e expressão dos atores sociais em sistemas culturais de escala global. A dimensão cultural carece de melhor atenção pelas pesquisas sobre empreendedorismo cultural, uma vez que, mais do que a economia e tecnologia, a cultura é o principal fundamento da criatividade (HARTLEY et al., 2015).

Pesquisadores no campo do empreendedorismo ainda não se debruçam de forma plena e robusta sobre o fenômeno do empreendedorismo cultural. Isso se agrava quando discutimos as relações do empreendedorismo cultural com a territorialidade. Dentro do vasto universo de pesquisas sobre empreendedorismo, as pesquisas focadas nas relações entre cultura e territorialidade são quase inexistentes. Embora ainda pouco abordada, a territorialidade é parte imprescindível na caracterização de um empreendimento cultural. Mesmo quando sabemos que o empreendedorismo cultural requer a interação da experiências vividas e crenças pessoais com um ambiente (ELIAS et al., 2018), este ambiente não é estudado a partir das teorias espaciais e territoriais. No contexto das economias culturais e criativas, sustentadas e dinamizadas pelas forças empreendedoras, pensar sua relação com as questões territoriais e espaciais não seria um caminho para tornar o desenvolvimento mais enraizado, distinto e robusto?

Cultivar as artes e o empreendedorismo cultural permite $\mathrm{o}$ florescimento da economia criativa, crescente nas cidades, regiões e países, por causa da identificação constante de oportunidades e da tangibilização de atividades culturais (KUHLKE et al., 2015). As artes e o empreendedorismo cultural já vem sendo compreendidos como dispositivos para ajudar a solucionar preocupações da sociedade, como uma forma de fomentar a sustentabilidade das artes, como fonte de independência para indivíduos na economia criativa e como chave no desenvolvimento de cidades criativas (KUHLKE et al., 2015).

Além disso, as economias criativas e culturais são abordadas do ponto de vista territorial, uma vez que ocorrem em territórios como bairros, cidades, regiões e países. O empreendedorismo cultural é primordial para entender e dinamizar a economia criativa. Por conseguinte, é necessário que se vislumbre a territorialidade também como parte vital do empreendedorismo cultural. Ora, as pesquisas sobre empreendedorismo têm se conectado com territórios como bairros, cidades, regiões e países, buscando compreender como eles se desenvolvem e se tornam locais de desenvolvimento econômico e industrial, centros de inovação e criatividade, arena para profissionais criativos e para minorias (STEYAERT, 2004). Apesar disso, a relação entre empreendedorismo cultural e território 
permanece incipiente nas pesquisas atuais (KUHLKE et al., 2015; HARTLEY et al., 2015; ELIAS et al., 2017).

O objetivo desta pesquisa é elaborar e discutir perspectivas e desafios para uma concepção territorial do empreendedorismo cultural. A pesquisa é teórico-conceitual, baseada em uma revisão sistemática das pesquisas acadêmicas publicadas sobre empreendedorismo, empreendedorismo cultural e territorialidade. Essa revisão foi realizada nas bases nacionais e internacionais (SPELL, SCIELO, Sage Publications, Routledge, Periódicos CAPES, JSTOR, EBSCO, Library of Congress, Emerald, Academy of Management, Amazon, Estante Virtual). As palavras-chaves utilizadas para a busca foram: empreendedorismo, entrepreneurship, empreendedor, entrepreneur, espaço, space, território, territory, comunidade, community, cultura, culture, cultural, cultural. A partir de uma primeira etapa de seleção (produções consistentes e coerentes) e análise deste material, mapeamos suas referências bibliográficas na busca de outras produções relevantes (artigos, livros, capítulos de livros, teses, dissertações, etc.). Ou seja, o processo de revisão ocorreu dentro de uma dinâmica de bola de neve, que chegou a um fim quando nenhuma referência emergia como nova e relevante. Encontramos e selecionamos vinte e cinto artigos científicos que abordam o empreendedorismo relacionado à territorialidade. Nenhuma pesquisa que relacione o empreendedorismo cultural com territorialidade foi encontrada.
A partir da análise sistemática de todas as produções selecionadas, desenvolvemos e propomos um novo olhar sobre a relação do empreendedorismo cultural com os campos da territorialidade, identidade e experiência, através do que chamamos de territorialidade como uma experiência identitária. Os resultados da pesquisa buscam contribuir com o avanço do conhecimento sobre a dimensão territorial do empreendedorismo cultural ao fornecer (a) uma visão integrada de como os conceitos territoriais são utilizados no campo do empreendedorismo, perspectivas espaciais para reorientar novas pesquisas sobre empreendedorismo cultural e (c) uma discussão sobre essa reorientação.

\section{EMPREENDEDORISMO CULTURAL E TERRITORIALIDADE: RELAÇÕES NECESSÁRIAS}

\section{Territorialidade nas Pesquisas sobre Empreendedorismo}

Várias pesquisas abordam a territorialidade a partir de distintas categorias territoriais em relação a tipos específicos de empreendedorismo (Quadro 1). No entanto, podemos observar a convergência em preocupações territoriais voltadas sobretudo para questões econômicas, sociais e ambientais. Nenhuma pesquisa tratou do empreendedorismo cultural. No seu conjunto, o foco das pesquisas recai em abordagens mais gerais do empreendedorismo ou tipologias específicas (por exemplo, empreendedorismo social).

Quadro 1 - Territorialidade nas Pesquisas sobre Empreendedorismo

\begin{tabular}{|l|l|l|}
\hline \multicolumn{1}{|c|}{$\begin{array}{c}\text { Tipos de } \\
\text { empreendedorismo }\end{array}$} & $\begin{array}{l}\text { Categoria } \\
\text { territorial }\end{array}$ & \multicolumn{1}{|c|}{ Relevância territorial do empreendedorismo } \\
\hline $\begin{array}{l}\text { Empreendedorismo } \\
\text { nativo }\end{array}$ & $\begin{array}{l}\text { Território } \\
\text { nativo }\end{array}$ & $\begin{array}{l}\text { O território aparece como um espaço a ser explorado de forma } \\
\text { sustentável. O empreendedorismo territorial refere-se à geração de renda } \\
\text { e solução de problemas sociais (AWATERE et al., 2017; PEARSON; } \\
\text { HELMS, 2013; KOKKRANIKAL; MORRISON, 2002; APRIL, 2008). }\end{array}$ \\
\hline $\begin{array}{l}\text { Empreendedorismo } \\
\text { comunitário }\end{array}$ & Comunidade & $\begin{array}{l}\text { O território aparece como local de desenvolvimento econômico e social. } \\
\text { O empreendedorismo territorial é tido como uma ferramenta para } \\
\text { amenizar a situação de pobreza das comunidades, que vivem } \\
\text { marginalizadas, ajudando a solucionar problemas sociais ignorados pelo } \\
\text { governo (LONDON; MORFOPOULOS, 2009; PEREDO; }\end{array}$ \\
\hline
\end{tabular}




\begin{tabular}{|l|l|l|}
\hline & & $\begin{array}{l}\text { CHRISMAN, 2006; IMAS et al., 2012; QUEIROZ et al., 2014; LOBO } \\
\text { et al., 2016; BARRAGAN; AYAVIRI, 2017; WANG; MORRELL, } \\
\text { 2015). }\end{array}$ \\
\hline $\begin{array}{l}\text { Empreendedorismo } \\
\text { urbano }\end{array}$ & $\begin{array}{l}\text { Cidade, } \\
\text { bairro }\end{array}$ & $\begin{array}{l}\text { O território é concebido a partir da perspectiva geopolítica, onde o } \\
\text { empreendedorismo surge como ferramenta para solução de problemas } \\
\text { causados pela injusta provisão de bens e serviços, como problemas } \\
\text { ambientais e socioeconômicos. O território serve como laboratório vivo } \\
\text { para o indivíduo empreendedor (MUNOZ; COHEN, 2015; MUNOZ; } \\
\text { COHEN, 2016; COHEN et al., 2016; CARVALHO et al., 2017; } \\
\text { CALVET-MIR; MARCH, 2019). }\end{array}$ \\
\hline $\begin{array}{l}\text { Empreendedorismo } \\
\text { rural }\end{array}$ & Espaço rural & $\begin{array}{l}\text { O território aparece como fonte de renda e desenvolvimento para a } \\
\text { economia rural, através da exploração do espaço físico com o turismo } \\
\text { (GORBUNTSOVA et al., 2018). Foco no aspecto econômico do } \\
\text { empreendedorismo. }\end{array}$ \\
\hline $\begin{array}{l}\text { Empreendedorismo } \\
\text { étnico }\end{array}$ & $\begin{array}{l}\text { Grupos } \\
\text { étnicos }\end{array}$ & $\begin{array}{l}\text { O território influencia o empreendedorismo, considerando que o } \\
\text { empreendedor influencia o grupo étnico com base no capital social. O } \\
\text { empreendedorismo territorial aparece como forma de desenvolvimento } \\
\text { econômico e engajamento dos grupos (CHOI, 2013; HEBERER, 2007). }\end{array}$ \\
\hline $\begin{array}{l}\text { Empreendedorismo } \\
\text { geográfico }\end{array}$ & $\begin{array}{l}\text { Espaço } \\
\text { geográfico }\end{array}$ & $\begin{array}{l}\text { O território é concebido como espaço geográfico, moldando o } \\
\text { empreendedorismo. O empreendedorismo aparece como atividade } \\
\text { social, ligado à cultura devido ao contexto das indústrias criativas } \\
\text { (STEYAERT; KATZ, 2004; SCHIRAY et al., 2017). }\end{array}$ \\
\hline
\end{tabular}

Fonte: Elaboração própria

No empreendedorismo nativo, as produções acadêmicas encontradas pesquisam as comunidades nativas, a exemplo da Maori. $\mathrm{Na}$ categoria do território nativo, o empreendedorismo surge como uma ferramenta de desenvolvimento financeiro e social para essas comunidades em situação de marginalidade. Um ponto importante levantado pelos pesquisadores do campo é a preocupação do empreendedorismo nativo em solucionar problemas sociais negligenciados pelos governos (PEARSON; HELMS, 2013). O foco dos estudos são as comunidades indígenas, em que o empreendedorismo é promovido como uma forma de geração de renda através das atividades desenvolvidas nas comunidades, como o turismo e o artesanato MORRISSON, 2002). No empreendedorismo nativo existe uma grande preocupação com o desenvolvimento sustentável e com o bemestar das comunidades nativas, dando uma perspectiva humanizada ao empreendedorismo, diferente da ideia de maximização dos lucros atribuída ao empreendedorismo pela sociedade. É um tipo de empreendedorismo com uma base filosófica proeminente, uma vez que se apoia nos princípios e valores dos nativos (AWATERE et al., 2017). O principal objetivo dos estudos é compreender o papel do empreendedor na construção de um capital social para essas comunidades (APRIL, 2008). Nesse contexto, o território nativo é visto como uma ferramenta de trabalho e geração de renda, para ajudar a solucionar os problemas sociais das comunidades que nele habitam. O território nativo é visto como um espaço físico, com potencial para ser explorado de forma sustentável e para ser pensado no intuito de desenvolver financeira e socialmente as comunidades indígenas.

As produções acadêmicas sobre empreendedorismo comunitário possuem uma abordagem mais ampla, trabalhando com tipos diferentes de comunidades. O campo possui forte ligação com o empreendedorismo social, aparecendo como uma ferramenta de desenvolvimento comunitário complementar (LONDON; MORFOPOULOS, 2009). Nesse contexto, o empreendedorismo comunitário é tido como uma forma de ajudar a amenizar situações crônicas de pobreza, levando em consideração o desenvolvimento sustentável das comunidades (PEREDO; CHRISMAN, 2006). Os empreendedores comunitários são oriundos de lugares e 
contextos excluídos, inclusive do contexto empreendedor, que privilegia o objeto da economia (IMAS et al., 2012). Um exemplo é o contexto das mulheres, onde a maioria dos estudos tratam das dificuldades que elas encontram no fazer empreendedor, negligenciando aspectos como o desenvolvimento individual e comunitário (WANG; MORREL, 2015). Dentro do contexto do empreendedorismo comunitário, foi possível encontrar um viés cultural, onde se levanta a importância da identidade cultural no fazer empreendedor (QUEIROZ et al., 2014). O turismo sustentável também aparece no contexto do empreendedorismo comunitário como um instrumento de auxílio ao desenvolvimento do território, ainda que de forma pouco presente na maioria das pesquisas da área (LOBO et al., 2016). O empreendedorismo comunitário busca compreender a relação entre empreendedorismo e desenvolvimento local, onde o território aparece como local de desenvolvimento social (BARRAGAN; AYAVIRI, 2017).

No empreendedorismo urbano, a noção de território se situa nas cidades e bairros. O empreendedorismo urbano busca compreender como indivíduos conseguem ajudar a resolver anomalias específicas de um território e promover o bem-estar urbano através do empreendedorismo (MUÑOZ; COHEN, 2016). O empreendedor urbano atua em locais onde há significantes problemas socioeconômicos, culturais e ambientais, utilizando o território como laboratório vivo. Ao invés de buscar oportunidades de mercado, o empreendedor urbano procura enxergar o território como um todo, focando em resolver problemas causados pela inadequada provisão de bens e serviços por parte do governo (COHEN et al., 2016). $\mathrm{O}$ empreendedorismo urbano também possui ligação com as áreas da cultura $\mathrm{e}$ turismo, que servem como ferramenta de auxílio ao desenvolvimento dos territórios (CARVALHO et al., 2017). É no empreendedorismo urbano que surge o conceito de jardinagem urbana, no contexto do empreendedorismo social, ocupando e ressignificando locais marginalizados dentro dos territórios (CALVET-MIR; MARCH, 2019).

Dos tipos de empreendedorismo encontrados, o empreendedorismo rural é o que concentra o menor número de produções acadêmicas. empreendedorismo rural é uma parte importante do processo de inovação de aproveitamento, desenvolvimento de comunidades e criação de empregos, aparecendo como aspecto vital para o desenvolvimento da economia rural (GORBUNTS OVA et al., 2018). A relação com o território aparece de forma superficial: o território é considerado como um gerador de fonte de renda $e$ desenvolvimento da economia rural. As comunidades indígenas também estão presentes no campo do empreendedorismo rural, em que a análise recai sobre a exploração do poder que cerca o desenvolvimento da indústria do turismo.

$O$ empreendedorismo étnico entende que o empreendedorismo foi um fator determinante para desenvolvimento econômico e de grupos étnicos ao longo da história (CHOI, 2013). As pesquisas sobre empreendedorismo étnico enfocam a relação do empreendedorismo com a identidade étnica. Nesse contexto, os empreendedores são portadores de símbolos étnicos e agentes modernizadores, ajudando a moldar a identidade do território em que os grupos habitam. Nessas pesquisas, o território influencia o empreendedorismo e o empreendedor influencia o grupo étnico (HEBERER, 2007). Um exemplo é a comunidade de Nuosu, na China, onde os empreendedores étnicos formam uma nova economia e elite, ajudando a moldar a consciência coletiva da comunidade em que estão inseridos. No

empreendedorismo geográfico, o empreendedorismo é considerado uma atividade social (STEYAERT; KATZ, 2004). As pesquisas buscam explorar e refletir sobre as implicações de se conceber o empreendedorismo, considerando-o mais como um fenômeno social do que 
econômico. São explorados os aspectos geopolítico, discursivo e social dos espaços onde o empreendedorismo é produzido na sociedade e o seu impacto na vida cotidiana. Dentro do campo, encontramos discussões sobre a economia criativa e seu potencial como alavanca de desenvolvimento social (SCHIRAY et al., 2017). Um exemplo é o da Favela da Mangueira, na cidade do Rio de Janeiro. O estudo mapeou dezessete iniciativas associadas à economia criativa na favela da Mangueira, no Rio de Janeiro. As iniciativas desenvolvem atividades artísticas e culturais que ajudam os jovens da comunidade a conhecer a história de suas famílias. Esse conhecimento ajuda a fortalecer os laços sociais e empoderamento individual, contribuindo para $\mathrm{o}$ desenvolvimento do empreendedorismo local. O estudo conclui que a dinâmica da economia criativa nas favelas da Mangueira também representa um caso de inovação social, usando ferramentas de tecnologia social (SCHIRAY et al., 2017).

Algumas constatações podem ser feitas a partir da análise desse conjunto de pesquisas sobre empreendedorismo e territorialidade. A primeira constatação é a predominância de uma concepção econômica, social e ambiental da territorialidade do empreendedorismo. Como visto na maior parte da produção acadêmica, o território aparece como uma ferramenta fundamental para a geração de renda, por vezes sendo a única fonte de ganho das comunidades. Em termos sociais, o território aparece como um espaço onde os empreendedores podem colocar suas ideias inovadoras em prática, ajudando a amenizar os problemas sociais e ambientais existentes em um determinado contexto, alcançando locais onde o governo não chega. Foi possível observar que o empreendedorismo é tido como uma alavanca para a resolução de problemas sociais, de engajamento de grupos e de desenvolvimento econômico, gerando transformações na estrutura socioeconômica local. Nesse contexto, a territorialidade aparece como um mecanismo auxiliar, servindo principalmente de laboratório para os empreendedores (local onde eles podem colocar em prática suas ideias inovadoras), como plataforma para a economia da inovação, como fonte de renda e de desenvolvimento social.

A segunda constatação indica que a dimensão cultural da territorialidade aparece de forma pontual. A dimensão cultural aparece de forma mais evidente no empreendedorismo de tipo nativo e étnico, que trabalham com comunidades indígenas e asiáticas, respectivamente. No caso dos indígenas, há um enfoque na cultura Maori que molda o empreendedorismo com base nos seus costumes e crenças. No empreendedorismo étnico das comunidades asiáticas, o empreendedorismo territorial é utilizado para perpetuar a cultura da comunidade, a exemplo da comunidade coreana na pesquisa de Choi (2013), parte de uma instituição religiosa. Nesta pesquisa, o empreendedorismo étnico é um fator chave para o desenvolvimento econômico de comunidades e ao longo da história, tem se mostrado vital para a dinâmica de comunidades e como oportunidade de desenvolvimento para minorias marginalizadas. As pesquisas abordam a cultura a partir de uma visão economicista, onde a mesma serve de auxílio para a geração de renda das comunidades.

A terceira constatação revela que a

dimensão territorial do empreendedorismo está associada a territórios e grupos marginalizados. $\mathrm{Ou}$ seja, as pesquisas apresentam limitações. não só na abordagem territorial, como nos objetos de investigação, em sua maioria, trabalhando com comunidades indígenas. É interessante observar que os estudos que não trabalham com comunidades indígenas, trabalham com outros tipos de minorias e grupos vulneráveis, a exemplo das mulheres, asiáticos e moradores de territórios marginalizados. Foram encontradas pesquisas que abordam territórios como comunidades, cidades, estados e arquipélagos, porém não encontramos nenhuma pesquisa que focasse em territórios como bairros e países. 
Territorialidade e Empreendedorismo Cultural: Carências e Necessidades

Com a análise das pesquisas encontradas, identificamos duas grandes carências no que diz respeito as relações do empreendedorismo cultural como campo da territorialidade. A primeira carência é a ausência de uma perspectiva cultural que enfatize a identidade e a experiência do empreendedorismo. Há uma predominância das concepções econômica, social e ambiental da territorialidade. Nelas, a cultura aparece de forma pontual e limitada. Na maioria das pesquisas, o aspecto cultural se concentra no turismo e artesanato, com apenas uma pesquisa que aborda a cultura do ponto de vista das economias criativas.

O território possui uma dimensão simbólica e cultural, através de uma identidade atribuída pelos atores sociais que o compõe (SAQUET; BRISKIEVICZ, 2009). Diante disso, é possível perceber que as temáticas da cultura e identidade estão intimamente ligadas dentro das teorias territoriais. A identidade pode contribuir para o processo de desenvolvimento da autonomia de atores sociais nos mais variados níveis sociais, especialmente os mais necessitados e desamparados pelas políticas públicas do Estado (SAQUET; BRISKIEVICZ, 2009). No que tange a experiência, podemos defini-la como sendo a forma pela qual o indivíduo conhece e constrói sua realidade, onde a forma como nos movimentos no espaço é diferenciada por ela (TUAN, 2013). O ser humano possui papel fundamental na formação de um território, conferindo-lhe conteúdo através de suas experiências. Compreender a cultura, identidade e as experiências dos atores sociais é crucial para compreender o território como um todo, uma vez que a cultura molda a identidade ao dar sentido à experiência e às escolhas identitárias (SAQUET; BRISKIEVICZ, 2009).

A segunda carência diz respeito a ausência de uma análise da perspectiva territorial do empreendedorismo cultural. As economias criativa e cultural são abordadas do ponto de vista territorial, uma vez que ocorrem em territórios como bairros, cidades e países e a sua íntima relação com a cultura é inegável. Se o empreendedorismo cultural é essencial para entender e dinamizar a economia criativa, torna-se imprescindível entender a territorialidade como parte fundamental do empreendedorismo cultural. As pesquisas sobre empreendedorismo têm se conectado com as cidades, buscando compreender como elas se desenvolvem e se tornam locais de crescimento econômico e industrial, centros de inovação e criatividade, espaço para profissionais criativos e para minorias (STEYAERT, 2004). Apesar disso, a relação entre empreendedorismo cultural e território se mostra ainda incipiente na produção acadêmica corrente (KUHLKE et al., 2015; HARTLEY et al., 2015; ELIAS et al., 2018).

Para os empreendedores culturais, é importante compreender o contexto com o qual vão trabalhar, buscando conhecer o quadro político e econômico das cidades e regiões, problemas locais, além do perfil de consumidores e trabalhadores. O contexto local é um composto das particularidades da comunidade local e do território. Para obter sucesso, o empreendedor cultural precisa se familiarizar com esse contexto (KUHLKE et al., 2015).

\section{PERSPECTIVAS TERRITORIAIS PARA AVANÇAR A PESQUISA SOBRE EMPREENDEDORISMO}

No intuito de contribuir com o
avanço das $\begin{array}{rr}\text { pesquisas } \\ \text { cultural }\end{array}$
empreendedorismo e
territorialidade, propomos
perspectivas teóricas do campo da
territorialidade: identidade e experiência.
Entendemos que essas perspectivas podem
abrir caminhos profícuos e relevante para
pesquisas futuras no campo do
empreendedorismo cultural, ao permitir
uma sofisticação teórica e um melhor
alinhamento com sua dimensão cultural.




\section{A Perspectiva da Territorialidade como Identidade}

A identidade possui papel fundamental nas discussões sobre territorialidade, sendo entendida como um processo relacional e histórico, efetivado cultural, econômica e politicamente (SAQUET; BRISKIEVICZ, 2009). Há algum tempo os estudos organizacionais abordam a identidade organizacional, considerando a identidade como processo, como dinâmica, como estratégia, como poder, como controle, como narrativa e como trabalho (DAVEL et al., 2016). Embora muito já se saiba sobre identidade organizacional, pouco se sabe sobre sua relação com a identidade do território em que ela está situada. O território se mostra uma dimensão crucial para a construção identitária, uma vez que a identidade é fruto das relações sociais e as mesmas necessitam de um lugar para se desenvolverem (DAVEL et al., 2016). A identidade territorial não é unitária, sendo intercalada por várias outras identidades e seus conteúdos simbólicos (SAQUET; BRISKIEVICZ, 2009).

$\mathrm{Na}$ perspectiva da territorialidade como identidade, o território é compreendido numa perspectiva integrada. O território é um domínio politicamente estruturado e como apropriação simbólica e identitária, inerente a uma determinada classe social. Nesse contexto, há uma conjugação entre os processos políticos e culturais como principais definidores de um território (HAESBAERT, 1997). Em sua constituição, o território envolve, ao mesmo tempo, uma dimensão simbólica e cultural, com base uma identidade atribuída pelos atores sociais que ali habitam, e uma dimensão político-disciplinar, como forma de controle desses atores. É através dos símbolos que se confere sentido às relações sociais, onde a identidade pode ter um caráter mais ou menos duradouro, a depender das condições de vida dos grupos sociais (SAQUET; BRISKIEVICZ, 2009).
Embora pouco explorada pelos pesquisadores de organizações, a identidade territorial está também ligada a muitas práticas organizacionais relacionadas a produtos e serviços. Produtos ou serviços podem se utilizar de uma identidade marcante, a ponto de se tornarem indissociáveis do território em que são produzidos, conseguindo se consolidarem como marcas regionais e nacionais, chegando ao ponto de ganhar destaque no âmbito da economia internacional (DAVEL et al., 2016). É possível identificar duas formas diferentes de identidades culturais. A primeira ocorre quando um determinado grupo social busca recuperar sua história por meio de uma cultura compartilhada que é representada pela identidade. A segunda é baseada no reconhecimento entre os atores sociais e suas reivindicações comuns. Os autores entendem a identidade territorial de maneira híbrida, ou seja, como um processo de relações sociais, econômicas, políticas e culturais (SAQUET; BRISKIEVICZ, 2009)

A força política e cultural dos grupos sociais que habitam um território influencia diretamente na formação da sua identidade territorial, ao passo em que a cultura possui a capacidade de moldar a identidade ao dar sentido às práticas identitárias (HAESBAERT, 1997). O território é tido como um espaço que não pode ser considerado estritamente natural, político, econômico ou cultural (HAESBAERT, 2011). Consequentemente, o território é definido com base nas relações sociais, culturais e políticas e no contexto histórico em que se insere. $O$ espaço geográfico, também chamado de território usado, é uma ligação entre o mundo e a sociedade, onde as ações e os objetos são indissociáveis, tornando-se uma instância social (SANTOS, 1996). Nesse contexto, a territorialidade pode ser compreendida como um processo de relações sociais, tanto políticas e culturais, como econômicas de um grupo social (SAQUET; BRISKIEVICZ, 2009). Assim, contextualizar historicamente o território torna-se sempre fundamental.

Em suma, a identidade pode ser compreendida de maneira híbrida, como um 
processo histórico e relacional, efetivado pela cultura, pela economia e pela política. A identidade territorial é constituída pelas relações territoriais que estabelecemos no dia a dia, envolvendo as obras materiais e imateriais produzidas pela sociedade, como as músicas crenças, valores, casas, etc. (SAQUET; BRISKIEVICZ, 2009). A identidade territorial pode ser concebida uma construção social, resultante das relações culturais e políticas que os grupos sociais estabelecem em um território (SANTOS; DAVEL, 2018). Território e identidade influenciam-se mutuamente, uma vez que são frutos das relações sociais e que não há relação social que aconteça descolada da dimensão territorial (SANTOS; DAVEL, 2018). A construção da identidade territorial leva à compreensão dos potenciais de identidade e ao reconhecimento das matrizes identitárias do território (CEZÉRIO; DAVEL, 2017, p. 271).

\section{A Perspectiva da Territorialidade como Experiência}

$\mathrm{Na}$ teoria da territorialidade, a experiência é um termo capaz de abranger as diferentes maneiras pelas quais o ser humano conhece e constrói sua realidade, onde essas maneiras podem ser diretas, como os cinco sentidos, ou indiretas, como o valor simbólico (TUAN, 2013). Constituída de sentimento e pensamento, a experiência é definida como a capacidade de aprender a partir das próprias vivências. A forma como nos movimentamos no espaço é diferenciada pela experiência. Podemos ter noção de espaço mobilizando o paladar, olfato e audição, mas para acessarmos a emoção ligada a experiência, a maioria das pessoas faz uso dos cinco sentidos conjuntamente, tornando a vivência mais rica (TUAN, 2013).

A percepção do espaço depende da qualidade dos sentidos e da capacidade da mente para extrapolar as informações recebidas pelo território. A forma como nos movimentamos no espaço é diferenciada pela experiência. Um objeto ou lugar atinge realidade concreta quando nossa experiência é total, ou seja, através dos sentidos e da mente. Não é possível definir o indivíduo, a comunidade e a sociedade sem inseri-los num determinado contexto territorial (HAESBAERT, 2011). Ao residir por muito tempo em um espaço, podemos conhecê-lo de forma intima. Entretanto, sua imagem não será necessariamente nítida, a menos que também possamos vê-lo de fora e possamos pensar em nossa experiência no lugar. Com efeito, a espécie humana é produtora de símbolos e possui como característica o apego de seus membros aos lugares. Os cientistas sociais tendem a encarar a cultura como fator explicativo para diferenças de entendimento do conceito de espaço e lugar entre os homens que habitam diferentes espaços (TUAN, 2013). Uma pessoa pode vivenciar um espaço de várias formas diferentes, ou até mesmo de mais de uma forma por vez.

A questão do território transita por diversas áreas, a exemplo da ciência política, economia, antropologia, sociologia e psicologia, cada uma em uma determinada perspectiva. Enquanto a geografia foca na materialidade do território, a economia, por exemplo, percebe o território como fator locacional ou como uma base de produção. $\mathrm{Na}$ perspectiva cultural, também chamada de simbólico-cultural, o território é visto como produto da apropriação simbólica de um grupo em relação ao seu espaço (HAESBAERT, 2011). A forma como as pessoas percebem o mundo e atribuem valores às suas partes é diferente. As culturas têm percepções diferentes sobre a elaboração dos esquemas espaciais, onde as semelhanças encontradas são derivadas da estrutura e valores do corpo humano. A cultura e a experiência têm profunda influência na interpretação do indivíduo sobre o espaço. O espaço é mais do que um ponto de vista ou sentimento fugaz, é uma condição para a sobrevivência biológica do ser humano (TUAN, 2013).

Para melhor apreender a noção de espaço a partir da perspectiva da experiência, é importante começarmos pela 
noção de espaço das crianças (TUAN, 2013). Apesar de as crianças estarem sob influências culturais constantes, que moldam suas ideias de espaço e lugar, é possível dizer que a criança não tem mundo. Tal afirmação é feita porque a criança não tem a capacidade de distinguir o seu eu do ambiente externo. A criança encara a mãe como sendo seu primeiro lugar, onde mais tarde entra a noção emocional, com a mãe se tornando uma fonte segura de abrigo e bem-estar físico-psicológico. A medida em que cresce, a criança passa a se apegar a objetos e não pessoas, até chegar ao momento de se apegar a localidades.

O espaço geográfico da criança cresce à medida que elas vão envelhecendo, mas não necessariamente em direção a escala maior. A criança estreita seus laços emocionais com espaços que são feitos na escala de idade delas. Crianças pequenas se contentam em se esconder em espaços pequenos, como móveis. Já crianças mais velhas buscam espaços maiores, como espaços na natureza ou construídos pelo ser humano. Ao envelhecermos, sentimos a necessidade de apoiarmos nossas necessidades emocionais em espaços e lugares, não necessariamente vinculando tal necessidade ao tamanho do lugar. Ao contrário da criança, o adulto pode atribuir um profundo significado a um espaço ao acumular sentimento no lugar durante os anos (TUAN, 2013).

Para a geografia, território e territorialidade são conceitos centrais, por dizerem respeito a espacialidade humana. Assim, o espaço é tido como categoria geral de análise e o território como conceito. Do ponto de vista epistemológico, o espaço é uma categoria vaga, enquanto o território é um conceito preciso (HAESBAERT, 2011). Apesar de dividir o espaço com outros animais, o ser humano responde ao espaço de maneiras complexas, que não competem aos outros animais. A pessoa humana possui papel fundamental na formação do espaço geográfico, assumindo a função de conferir conteúdo às formas espaciais (SANTOS, 1996). Sem a ação humana, o espaço seria paisagem, pois é o ser humano é que lhe atribui sentido. A configuração territorial e o espaço são coisas distintas. O território vem da sua materialidade, enquanto o espaço reúne a materialidade à vida que o anima (SANTOS, 1996). O território corresponde aos complexos naturais e construções feitas pelo ser humano, sendo construído historicamente como a negação do mundo natural.

\section{A PERSPECTIVA DA TERRITORIALIDADE COMO EXPERIÊNCIA IDENTITÁRIA: PROSPECÇÕES E DESAFIOS PARA A PESQUISA EM EMPREENDEDORISMO}

A territorialidade do empreendedorismo poder ser pesquisada e concebida sob uma nova perspectiva baseada na identidade e experiência. Chamamos esse novo olhar de territorialidade como experiência identitária, onde as experiências dos atores sociais caracterizam o território, ao passo em que a identidade territorial é fortalecida pelo empreendedorismo. A identidade é produto dos processos históricos e relacionais de um indivíduo ou grupo social, configurando-se como um patrimônio territorial (SAQUET; BRISKIEVICZ， 2009). A experiência refere-se a forma como o ser humano se movimenta e vivencia um ambiente (TUAN, 2013). Territorialidade, identidade e experiência acontecem de forma simultânea, onde uma influência a outra dentro de uma relação dinâmica.

A territorialidade como experiência identitária é uma perspectiva integradora, pois as teorias sobre identidade e experiência se misturam e se complementam, no contexto territorial. Assim, a identidade é construída e fortalecida a partir das experiências dos atores sociais com $\mathrm{o}$ território. A experiência depende do território para que aconteça, enquanto é constituído pelas experiências de quem o habita, uma vez que são os seres humanos que lhe agregam conteúdo, transformando um lugar em território. $\mathrm{Na}$ visão da territorialidade como 
experiência identitária, o ser humano percebe o território a partir de suas dimensões culturais, políticas e sociais. Nesta visão, a pessoa humana possui papel fundamental na formação da identidade do território. Cada pessoa vivencia e experimenta um território de maneira diferente, o que nos leva a entender a identidade territorial como fruto das múltiplas e dinâmicas experiências de quem o compõe. Com efeito, a territorialidade como experiência identitária se aplica para a compreensão de um território a partir das experiências vividas não só pelos seus atores sociais, mas pelo território em si. A partir dela, é possível analisar os acontecimentos históricos e culturais que moldaram a identidade de um lugar, bem como compreender como esses acontecimentos moldaram a identidade de seus atores sociais. Dentro dessa perspectiva, o ser humano e o território estão intimamente ligados, sofrendo influência mútua.

No contexto do empreendedorismo cultural, a identidade e experiência territorial se apresentam como uma forma de compreender o território como um todo. Os empreendimentos culturais se apoiam em experiências vividas e crenças pessoais, buscando compreender o processo pelo qual os empreendedores experimentam e interagem com um ambiente. $\mathrm{O}$ empreendedorismo cultural se faz importante para as economias criativas, uma vez que torna o território culturalmente e criativamente dinâmico. Considerando que as economias criativas se desenvolvem em territórios, compreender a territorialidade do empreendedorismo cultural se faz necessário. Nesse contexto, os atores sociais fazem parte do processo de produção criativa, em que a dimensão identitária e experiencial são chaves para a compreensão da prática empreendedora e para desenvolvimento das economias criativas.

A experiência é um aspecto importante para as economias criativas, uma vez que ela combina a identidade pessoal e as expressões dos atores sociais ao sistema de escala global que é a cultura. Dentro desse contexto, compreender a forma como as pessoas vivenciam e se comportam em um território se faz fundamental para o empreendedorismo cultural. Promover o empreendedorismo cultural a partir de uma lógica territorial baseada na identidade e na experiência permite o florescimento da economia criativa, crescente nas cidades e regiões, por causa da identificação constante de oportunidades e tangibilização de atividades culturais (KUHLKE et al., 2015). As economias criativas produzem valor cultural, econômico, social e comunitário em um território. Assim, o empreendedorismo cultural impacta e é impactado pelo fortalecimento da identidade territorial.

Para adoção da perspectiva da territorialidade como experiência identitária, foram identificados dois grandes desafios de pesquisa. O primeiro desafio diz respeito à forma de como aprofundar as questões sobre cultura, territorialidade, identidade e experiência nas pesquisas sobre empreendedorismo. Embora a presente pesquisa seja uma fonte de informação sobre os temas, ela representa apenas o início da discussão sobre a territorialidade como experiência identitária. As investigações sobre essa temática ainda podem ser enriquecidas pela grande e vasta gama de pesquisas existentes sobre territorialidade, identidade e experiência. Para aprofundar as questões levantadas, os pesquisadores podem buscar pesquisas e teorias em outras áreas, como a geografia, a fim de compreender melhor as relações entre territorialidade, cultura, identidade e experiência. É necessário que o(a) pesquisador(a) tenha cuidado com a alta carga teórica existente. Embora possa ser compreendida como um ponto positivo, também se mostra um desafio para o(a)s pesquisadore(a)s.

$O$ segundo desafio diz respeito a escolha de uma abordagem metodológica adequada para pesquisar empiricamente a territorialidade como experiência identitária do empreendedorismo cultural. 
Pesquisar essa nova perspectiva gera uma reflexão sobre qual metodologia seria mais adequada, uma vez que ela possui vários aspectos a serem analisados de forma integrada. A metodologia escolhida deve ser capaz de apreender o empreendedorismo territorial e suas relações com a cultura, territorialidade, identidade e experiência, buscando compreender suas singularidades. Uma abordagem metodológica poderosa para compreender a territorialidade como experiência identitária é a etnografia, uma vez que o método busca compreender o objeto de estudo a partir da criação de sentidos (GOBO et al., 2017), da sensorialidade (PINK, 2009; MARINS; DAVEL, 2020a) e da caminhada consciente (JUNG, 2014). Dentro desses sentidos, destacamos a observação participante, já que a mesma considera as interações entre o pesquisador e os atores sociais, auxiliando na compreensão e o comportamento de um indivíduo ou grupo em determinado espaço.

\section{TERRITORIALIZAÇÃO EMPREENDEDORISMO}

DO

\section{CULTURAL: DISCUSSÕES IMPLICAÇÕES}

Embora estudos mais recentes apontem a importância a relação entre empreendedorismo cultural e territorialidade, a avanço ainda é lento e tímido. Se comparado ao vasto universo de estudos sobre empreendedorismo, a quantidade de pesquisas sobre empreendedorismo cultural ainda é incipiente, diante da importância do tema para a sociedade. As pesquisas mapeadas possuem abordagens teóricas bastante semelhantes, limitadas a estudar o empreendedorismo territorial de uma perspectiva econômica, social e ambiental. Dentro desse contexto, o território aparece de forma teoricamente limitada e fora do foco, além de o empreendedorismo ser abordado a partir de uma perspectiva mais próxima da tradicional, ou seja, voltado para a geração de riquezas econômicas dentro a perspectiva economicista (DAVEL; CORA, 2016). Há também uma limitação nos objetos empíricos de pesquisa, com a maioria concentrado em comunidades indígenas, focando $\mathrm{o}$ empreendedorismo na exploração do território em que habita a comunidade para o turismo.

A presente pesquisa apresenta quatro grandes implicações, duas de ordem teórica, uma de ordem metodológica e uma de ordem prática. A primeira implicação é fomentar discussões sobre as relações do empreendedorismo com a cultura, territorialidade e experiência identitária. Propomos uma compreensão ampla e diversa da territorialidade do empreendedorismo, através da inclusão das ideias sobre experiência e identidade. No que se refere a territorialidade como experiência identitária, foi necessário conhecer pesquisas para além da administração, como pesquisas no campo da geografia, a fim de propor uma nova perspectiva teórica. A partir da perspectiva da territorialidade como experiência identitária, buscamos abrir novos caminhos de pesquisa no campo do empreendedorismo, em especial no campo do empreendedorismo cultural. Assim, os resultados da pesquisa contribuem para o amadurecimento das discussões sobre territorialidade no empreendedorismo cultural.

A segunda implicação é a promoção de uma compreensão mais detalhada das singularidades do empreendedorismo cultural, bem como sua importância para o setor da economia criativa. A perspectiva da territorialidade como experiência identitária no empreendedorismo cultural se mostra uma referência interessante, uma vez que as economias criativas combinam identidade e expressão dos atores sociais a sistemas culturais de escala global. Com essa nova perspectiva, buscamos abrir novos caminhos de pesquisa, através de um olhar que busca compreender as origens das práticas culturais e como elas se conectam com pessoas e territórios. Estudar as economias criativas é um desafio, uma vez que vai de encontro as distinções 
disciplinares existentes. Essas distinções acontecem entre as ciências sociais, onde a economia é estudada, das ciências humanas e artísticas, onde a cultura é o foco (HARTLEY et al., 2015).

A terceira implicação é auxiliar os pesquisadores na escolha de uma metodologia de pesquisa adequada para o estudo da territorialidade como experiência identitária. Entendemos que a etnografia seja a forma mais adequada de explorar a territorialidade como experiência identitária. $\mathrm{O}$ método busca compreender o objeto de estudo a partir do eixo dos sentidos, em especial a observação (GOBO et al., 2017), a sensorialidade (PINK, 2009; MARINS; DAVEL, 2020a) e a caminhada consciente (JUNG, 2014). A observação participante considera as interações entre o pesquisador e os atores sociais, sendo crucial para entender o comportamento de um indivíduo ou grupo em determinado espaço. Como forma de complementar a etnografia, sugerimos o uso dos recursos audiovisuais, capazes de fornecer uma visão mais completa do objeto. Jung (2014) apresenta o conceito de "caminhada consciente", onde andar pelo território de estudo de forma consciente ajuda a melhor compreender o lugar, suas particularidades e seu povo.

A quarta implicação é de ordem prática, na medida em que os resultados da pesquisa podem auxiliar professores, formadores de empreendedores, empreendedores, além de gestores de políticas públicas. Os resultados desta pesquisa podem servir como apoio para aprimorar a prática de empreendedores e gestores de políticas públicas, pois fornecem a formadores de empreendedores um conhecimento mais sintonizado com a importância do território para o desenvolvimento do empreendedorismo cultural nos territórios criativos. Para os profissionais do setor público, a discussão se mostra relevante por poder servir como material de apoio à elaboração de políticas públicas que busquem desenvolver a relação entre empreendedorismo cultural e territorialidade. Ressaltamos a importância do papel do empreendedor cultural no desenvolvimento de territórios, bairros e cidades. Para os professores, serve como fomento a discussão do empreendedorismo cultural e territorial em sala de aula, assunto até o momento pouco abordado nas universidades do país.

\section{CONCLUSÕES}

Este artigo ofereceu um novo olhar sobre os temas de empreendedorismo, cultura, territorialidade e suas relações. $\mathrm{O}$ empreendedorismo cultural é um tema emergente e suas relações com a identidade e territorialidade precisam ser melhor exploradas. Uma ampla busca nos permitiu constatar que o número de estudos sobre empreendedorismo territorial é, de fato, inexpressivo dentro do amplo universo dos estudos sobre empreendedorismo. Ainda assim, os estudos existentes abordam questões extremamente relevantes e reafirmam o que já é discutido na produção acadêmica existente sobre o tema. Indo além da questão do território, é notável que a cultura, embora seja parte fundamental da formação da identidade de um território, é tratada de forma secundária, assim como a perspectiva economicista do empreendedorismo prevalece.

Os resultados da pesquisa nos convidam a pensar o território de forma integrada, ou seja, como resultado de um conjunto de fatores culturais, políticos e econômicos. A territorialidade como experiência identitária busca compreender a territorialidade de forma mais complexa e dinâmica do que apresentadas nas pesquisas atuais. Essa nova perspectiva provoca uma compreensão do território de uma de forma mais completa, identificando e entendendo suas particularidades e de seus atores sociais. Dentro dessa perspectiva não é possível dissociar a identidade territorial dos grupos sociais que ali habitam, uma vez que a força cultural e política desses grupos é o que lhe define. 
Quando falamos de empreendedorismo nas esferas artística e cultural, não significa que o discurso econômico passa a inexistir. $\mathrm{O}$ empreendedorismo não é um conceito unitário e estático, geralmente dependendo da integração de dois ou mais discursos (um econômico e outro cultural, por exemplo). O empreendedorismo é capaz de afetar a percepção das coisas e as formas como as pessoas se envolvem com um determinado espaço. Como proposto com a perspectiva da territorialidade como experiência identitária, buscamos que o empreendedorismo cultural seja visto de forma mais ampla, abarcando aspectos como o social, econômico, político e cultural. Entendemos que o empreendedorismo pode ser considerado uma intervenção criativa, com o poder de aumentar não só a capacidade de gestão, mas a capacidade social da sociedade (HJORTH, 2013).

\section{REFERÊNCIAS}

APRIL, W. I. Experiential learning from the Khoi-Khoi (Namibia) and Maori (New Zealand) Communities, The International Journal of Entrepreneurship and Innovation, v. 9, n. 2, p. 103-110, 2008.

AWATERE, S.; MIKA, J.; HUDSON, M.; PAULING, C.; LAMBERT, S.; REID， J. Whakatipu Rawa Ma Nga Uri Whakatipu: Optimising the 'Maori' in Maori Economic Development. AlterNative: An International Journal of Indigenous Peoples, v. 13, n. 2, p. 80-88, 2017.

BARRAGAN, M. C.; AYAVIRI, V. D. Innovación y emprendimiento, y su relación con el desarrollo local del pueblo de Salinas de Guaranda, Provincia Bolívar, Ecuador. Información tecnológica, v. 28, n. 6, p. 71-80, 2017.

CARVALHO, C. D. M. B.; CUTRIM, K. D. G.; COSTA, S. R. Empreendedorismo cultural e turismo: Perspectivas para desenvolvimento das indústrias criativas no bairro da Madre Deus, São Luís (Maranhão, Brasil), Boletim do Museu Paraense Emilio Goeldi: Ciências Humanas, v. 12, n. 2, p. 629-646, 2017.

CEZÁRIO, H.; DAVEL, E.; SANCHO QUEROL, L. Tecnologia social das mobilizações: identidade e participação na gestão de iniciativas museológicas comunitárias, Museologia e Patrimônio, v. 10, n. 2, p. 261-282, 2017.

CHOI, H. Religious institutions and ethnic entrepreneurship: The Korean ethnic church as a small business incubator. Economic Development Quarterly, v. 24, n. 4, p. 372-383, 2010.

COHEN, B.; ALMIRALL, S.; CHESBROUGH, $\mathrm{H}$. The city as a lab: open innovation meets the collaborative economy. California Management Review, v. 59, n. 1, p. 5-13, 2016.

COHEN, B.; MUÑOZ, P. Toward a theory of purpose-driven urban entrepreneurship. Organization \& Environment, v. 28, n. 3, p. 264-285, 2015.

DAVEL, E.; CORÁ, M. A. J. Empreendedorismo cultural: cultura como recurso retórico, processo de criação e de consumo simbólico. Políticas Culturais em Revista, v. 9, n. 1, p. 363-387, 2016.

DASKALAKI, M.; HJORTH, D.; MAIR, J. Are entrepreneurship, communities, and social transformation related? Journal of Management Inquiry, v. 24, n. 4, p. 419423, 2015.

ELIAS, S. R. S. T. A.; CHILES, T. H.; DUNCAN, C. M.; VULTEE, D. M. The Aesthetics of Entrepreneurship: how arts entrepreneurs and their customers co-create aesthetic value, Organization Studies, v. 39, n. 2-3, p. 345-372, 2018.

GORBUNTSOVA, T., DOBSON, S., PALMER, N. Rural entrepreneurial space and identity: A study of local tour operators 
and 'the Nenets' indigenous reindeer herders, International Journal of Entrepreneurship and Innovation, v. 19, n. 4, p. 261-272, 2018.

\section{GOBO, G., MOLLE, A. Doing}

Ethnography. 2. ed. London: Sage

Publications, 2016.

HAESBAERT, R. O mito da desterritorialização: do "fim dos territórios" à multiterritorialidade. Rio de Janeiro: Bertrand, 2011.

HAESBAERT, R. Des-territorialização e identidade: a rede "gaúcha" no nordeste. Rio de Janeiro: EDUFF, 1997.

HARTLEY, J., WEN, W., LI, H. S. Creative economy and culture: challenges, changes and futures for the creative industries. London: Sage Publications, 2015.

HAUSMANN, A.; HEINZE, A. Entrepreneurship in the cultural and creative industries: insights from an emergent field. Artivate: A Journal of Entrepreneurship in the Arts, 5, n. 2, p. 7-22, 2016.

HEBERER, T. Entrepreneurs and ethnic identity. In: HEBERER, T. (Ed.). Doing business in rural China: Liangshan's new ethnic entrepreneurs. Seattle: University of Washington Press, p. 186205, 2007.

HJORTH, D. Public entrepreneurship: desiring social change, creating sociality, Entrepreneurship and Regional Development, v. 25, n. 1-2, p. 34-51, 2013.

IMAS, J. M.; WILSON, N.; WESTON, A. Barefoot entrepreneurs. Organization, v. 19, n. 5, p. 263-285, 2012.

JUNG, Y. Mindful Walking: The serendipitous journey of community-based ethnography, Qualitative Inquiry, v. 20, n. 5, p. 621-627, 2014.
KOKKRANIKAL， J.; MORRISON，A. Entrepreneurship and sustainable tourism: the houseboats of Kerala. Tourism and Hospitality Research, v. 4, n. 1, p. 7-20, 2002.

KUHLKE, O., SCHRAMME, A., KOOYAMA, R. Creating cultural capital: cultural entrepreneurship in theory, pedagogy and practice. Utrecht: Eburon Academic Publishers, 2, p. 9821012, 2016.

LONDON, M.; MORFOPOULOS, P. R. G. Social entrepreneurship: how to start successful corporate social responsibility and community-based initiatives for advocacy and change. Abingdon: Routledge, 2019.

MARINS, S. R.; DAVEL, E. Etnografia estética na pesquisa em estudos organizacionais: princípios, processos e desafios. Revista Brasileira de Estudos Organizacionais, 7, n. 2, p. 1-39, 2020a.

MARINS, S. R.; DAVEL, E. P. B. Empreendedorismo cultural e artístico: veredas da produção acadêmica. Revista Pensamento Contemporâneo em Administração, 14, n. 4, p. 115-140, 2020b.

MUÑOZ, P.; COHEN, B. The making of the urban entrepreneur. California Management Review, v. 59, n. 1, p. 79-91, 2016.

PEARSON, C. A. L.; HELMS, K. Indigenous social entrepreneurship: the Gumatj clan enterprise in East Arnhem Land. The Journal of Entrepreneurship, v. 22, n. 1, p. 43-70, 2013.

PEREDO, A. M.; CHRISMAN, J. J. Toward a theory of community-based enterprise. Academy of Management Review, v. 31, n. 2, p. 309-328, 2006. 
PINK, S. Doing sensory ethnography. London: Sage Publications, 2009.

QUEIROZ, M. S. de A.; PINHO, V. de S.; CARNEIRO, S. N. V. O Desafio do empreendedorismo local: uma perspectiva cultural e familiar em narrativas. Revista Expressão Católica, v. 3, n. 1, p. 228-250, 2014.

SANTOS, M. A Natureza do espaço: técnica e tempo, razão e emoção. São Paulo: EDUSP, 2006.

SANTOS, F. P., DAVEL, E. P. B. Gestão de equipamentos culturais com base na identidade territorial, Revista Gestão \& Conexões, v. 7, n. 2, p. 7-42, 2018.

SAQUET, M. A.; BRISKIEVICZ, M. Territorialidade e identidade: um patrimônio no desenvolvimento territorial. Caderno Prudentino de Geografia, v. 31, n. 1, p. 3-16, 2009.

SCHIRAY, D. M.; CARVALHO, C. C.; AFONSO, R. Creative economy as a social technology approach: A case study in favela da Mangueira, Rio de Janeiro, Brazil. Academia Revista Latinoamericana de Administración, v. 30, n. 4, p. 508-528, 2017.

STEYAERT, C.; KATZ, J. A. Reclaiming the space of entrepreneurship in society. Entrepreneurship and regional development. Entrepreneurship \& Regional Development, v. 16, n. 3, p. 179196, 2004.

SILVA, M. C. de A. Notas etnográficas sobre o empreendedorismo em favelas cariocas. Etnográfica, v. 21, n. 3, p. 585598, 2017.

STEYAERT, C.; KATZ, J. Reclaiming the space of entrepreneurship in society: geographical, discursive and social dimensions. Entrepreneurship \& Regional Development, v. 16, n. 3, p. 179196, 2004.

TUAN, Y. Espaço e lugar: a perspectiva da experiência. Lodrina: EDUEL, 2013.

\footnotetext{
i Joyce Neri dos Reis Neves

Mestrado e Graduação em Administração pela Escola de Administracão, Universidade Federal da Bahia. Pesquisa sobre empreendedorismo cultural, territorialidade, identidade, valor simbólico e cultura.
}

\section{ii Eduardo Paes Barreto Davel}

Professor na Escola de Administração da Universidade Federal da Bahia. Pesquisador no CIAGS Centro Interdisciplinar de Desenvolvimento e Gestão Social (UFBA) e no NPGA - Núcleo de Pósgraduação em Administração (UFBA). Pós-doutorado em Administração pela Nova School of Business and Economics da Universidade Nova de Lisboa (Portugal). Ph.D. em Administração pela École des Hautes Études commerciales de Montreal (Canadá). Pesquisador visitante na Graduate Faculty of Political and Social Science da New School for Social Research (New York, EUA). Coordenador do coletivo de pesquisa OCA - Organizações, Cultura e Arte (CNPq). Editor da O\&S Revista Organizações \& Sociedade. Editor associado da RAE - Revista de Administração de Empresas e da RIGS - Revista Interdisciplinar de Gestão Social. Pesquisa e publica sobre empreendedorismo cultural, educação em Administração, métodos qualitativos de pesquisa, aprendizagem, criatividade, cultura, arte e estética nas organizações. 